SB 371

. 58

Copy 1 
VITED STATES DEPARTMENT OF AGRICULTURE

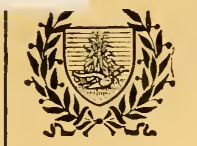

BULLETIN No. 864

Contribution from the Bureau of Markets GEORGE LIVINGSTON, Chief

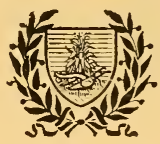

Washington, D. C.

PROFESSIONAL PAPER

July 28,1920

\section{A PEACH-SIZING MACHINE.}

By Manley Stockton, Investigator in Marketing, and J. F. Barghausen, Investigator in Agricultural Technology.

The sizing machine described in this bulletin was developed to meet a demand from peach growers for a simple and efficient machine that would accurately and carefully size and distribute peaches to the packing bins. In addition to those features which are always highly desirable in sizing machines, such as sufficient capacity for economical operation, substantial construction, and freedom from delicate adjustments, it was necessary to produce at a reasonable cost (the estimated cost of building single machines at the present price of materials should not exceed \$450), a machine which would not injure tender fruit by bruising or roughening the pubescence. Several sizers were in use in the northern and southern sections when the first experimental machine was built and put in the field, but existing types were open to the general objection that they were too expensive for the smaller grower or, if relatively inexpensive, either were not accurate enough or handled the fruit too roughly.

While the sizer described herein (see fig. 1) was developed primarily to meet the needs peculiar to the packing of peaches in 6-basket carriers, it may also be used, with a few slight changes in the bin construction, for jumble packing of bushel baskets. Further more, although the bureau does not officially indorse its use for sizing other crops, it is believed that this machine may be adapted to the sizing of other fruits, such as pears and apples. Where barrel packs are used for apples and no necessity exists for sizing the crop into numerous exact size classes, as is the case in box packing, this machine could probably be used with as good results as any other machine which sizes the fruit by measurement.

\section{CONSTRUCTION.}

In designing this machine an effort was made to specify as many standard parts as possible in order to facilitate construction. In the conveyer section (fig. 2) the wood framework is simply made and $180761^{\circ}-20-$ BulL 864 
serves as a structure to carry the roller sorting conveyer. 'The conreser is made by joining a series of wood rollers to a standard drive chain made of alternate D-5 and plain No. 45 links. The roller conveyer is carried up an incline of $23^{\circ}$, as illustrated in figure 1. This slope may be reduced by lengthening the belt, but the conveyer can not be operated successfully if it is made steeper, as some of the larger fruit would be bruised by rolling back. Tho rollers are 2 ! inches in diameter and each is reamed out at both ends to receive the pins on the D-5 links in the drive chains. The hopper or feed, which is hearily padded and sloped slightly to permit the fruit to roll to the

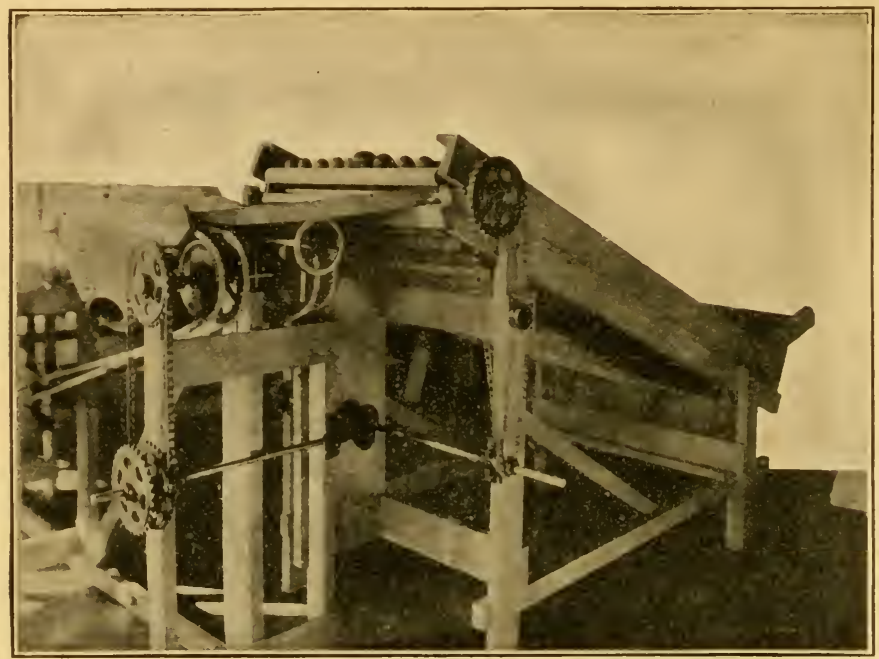

FIG. 1. - In order to make the machine more compact the sorting conveyer is joined to the sizer section at right angles. Note the continuous bins and packing bench and also the tracks which carry the ropes. The galvanized iron distributers seen at the ends of the ropes a:e used to divert the fruit to all parts of the end bin.

sorting conveyer, holds from a half bushel to a bushel of peaches. Some sort of chute should be attached to the sides of this conveyer at about halfway up the incline in order to provide a convenient means for the disposal of defective fruit by the sorters.

Figure 3 shows a cross section of the sizing mechanism and hins. Rope sizers resembling this one in a general way have been in use to a limited extent for many years. This machine is an improvement over others of the same type, because the tracks carrying the sizing ropes can be adjusted easily and quickly to any desired width while the machine is in operation by the device shown in figures 4 and 5 and also because the ropes are joined by a coupling which obviates the use of a

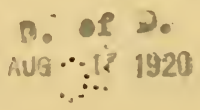


cumbersome splice. The crop is sized and distributed to packing bins having adequate space to accommodate ten to fifteen packers, who normally can pack the fruit fast enough to keep up with the work when the machine is running at full capacity.

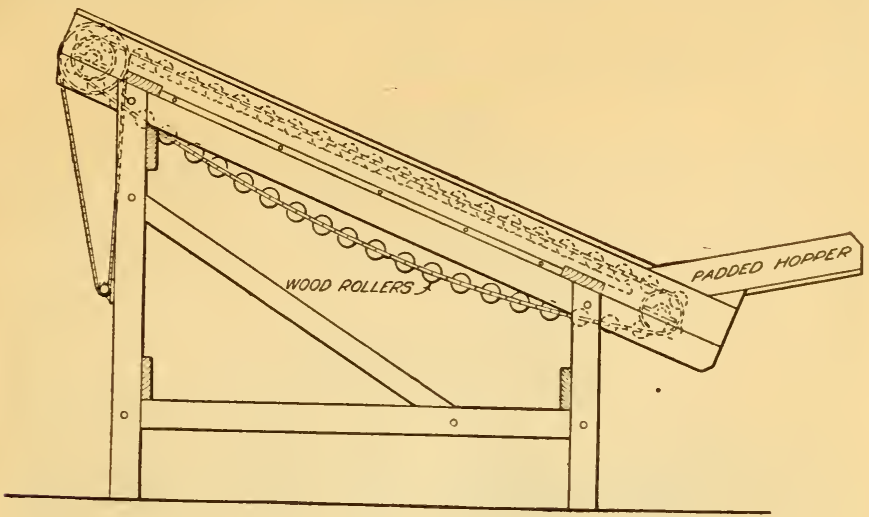

FIg. 2.-Side view of conveyer.

The tracks are supported by overhead iron braces attached to the central structure of the sizing section in such a way that the peaches have an unobstructed path in dropping through to the packing bins. The tracks in which the ropes travel are made of straight-grained white pine and are grooved out, as illustrated, to carry the ropes and to

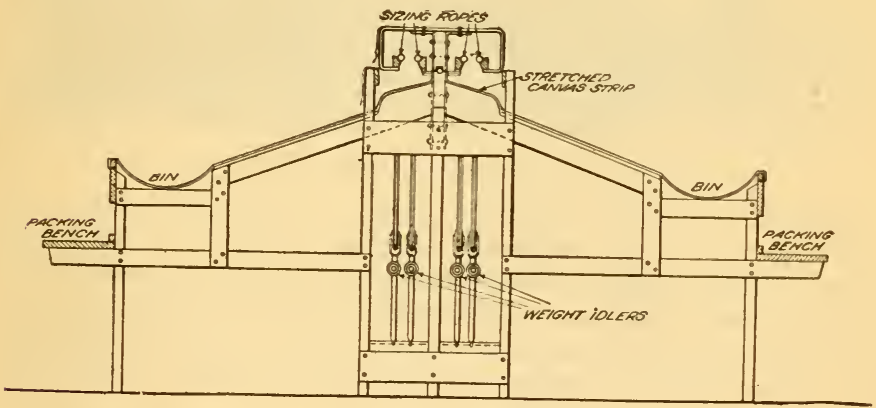

FIg. 3.-Cross-section view.

keep them accurately lined and exactly spaced throughout their length. The ropes are $\frac{3}{4}$-inch 3 -strand cotton rope and are very flexible. This flexibility makes it casier to keep the rope in the grooves. The ropes are also held in the grooved tracks by the tension produced by weight idlers under the machine. A piece of stretched 
canvas extends the length of the machine immediately under the opening between the tracks, to receive the fruit from the ropes and break the fall into the sloping bins. This strip is fastened to a ratchet drum at one end by which it may be tightened. The bins (see fig. 1), which slope about $20^{\circ}$, are in two parts; the sloping floor is heavily. padded and the bin pockets are formed by the loose canvas at the bottom, from which the fruit is taken by the packers.

\section{OPERATION.}

The peaches from the field are placed in the feeding hopper and fed in regular amounts into the spaces between the rollers as they are

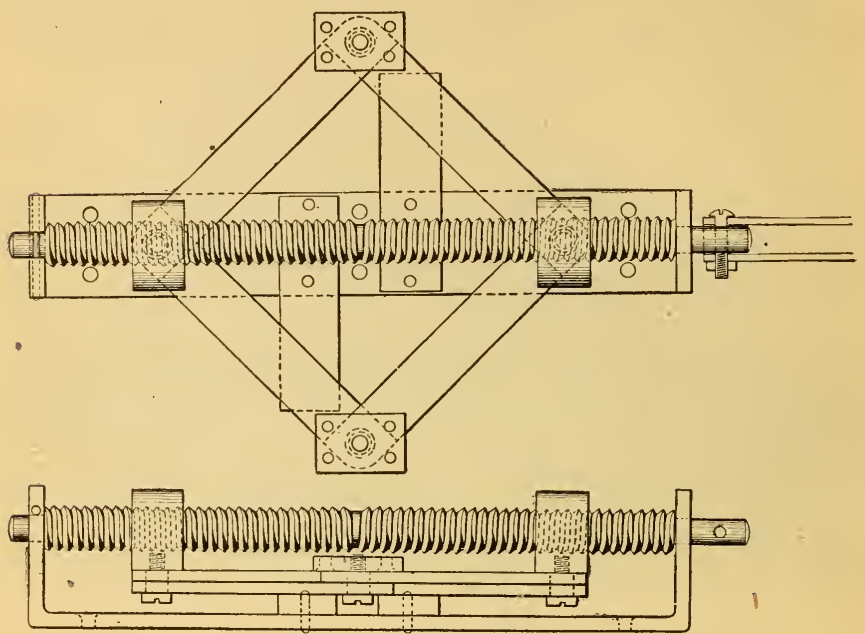

Fig. 4.-Detail of screw-controlled track adjuster.

presented. The rollers revolve as they travel up the incline, thus revolving the peaches which rest on them as they pass before the sorters. This is a great aid to sorting, for it makes unnecessary the turning of the fruit by hand in order to see the entire surface and therefore makes it possible for more efficient work to be done by fewer people than is the case where an endless canvas belt or an inclined chute is used for this purpose.

The sorters remove the defective specimens not intended for packing and place them in baskets or chutes attached to the sides of the conveyer frame. When the peaches reach the upper end of the conveyer they are delivered to a divided galvanized-iron chute that directs half of the fruit to one set of sizing ropes and half to the other. 
The ropes at this end of the machine are parallel and remain so for the first 3 feet. They are spaced to permit all fruit too small for packing to drop through into a canvas chute which delivers it into a basket or bin. After the first 3 feet the ropes begin to diverge and continue to do so till they reach the far end of the machine. The amount of divergence of the ropes is governed by the sizes desired in the bins. When the sizes are uniform and an equal distribution is desired to all bins the divergence will be less per foot than if there were a wide variation in the sizes of the fruit passing over the ropes. One of each pair of ropes travels slightly faster than the other, which tends to

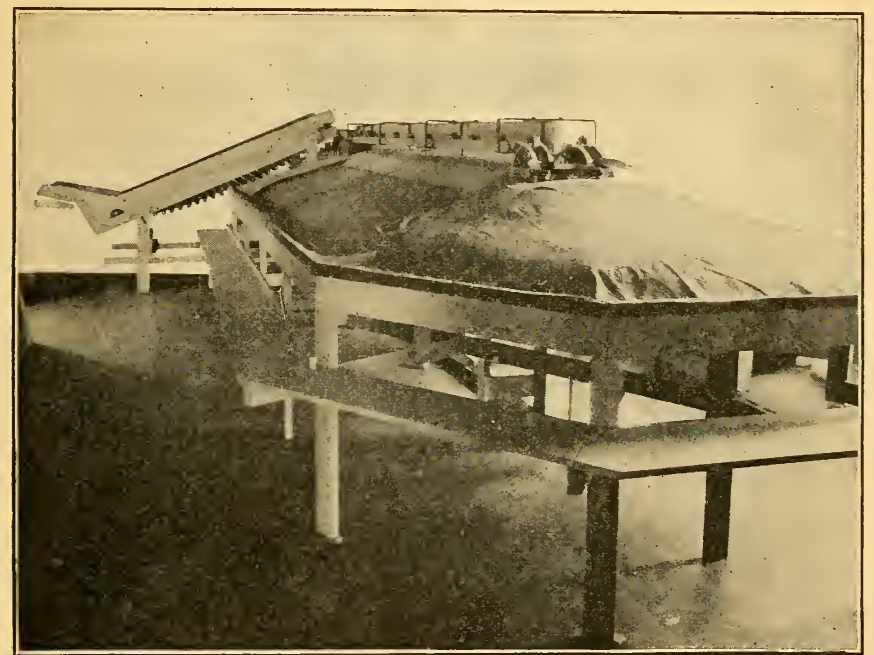

FIG. 5.-View showing the driving pulleys, the track-adjusting wheel, and the galvanized iron chute used to distribute the fruit from the roller-sorting conveyer to the sizing unit.

cause the peaches to straighten out lengthwise on the ropes, so that the transverse diameter is subjected to measurement. Very few peaches ever get on the ropes crosswise, as the $V$-shaped trough which extends for the first 3 feet serves to straighten them out. Thus the peaches are sized on the basis of their minimum transverse diameter.

The largest peaches go over the end of the ropes and pass over galvanized-iron adjustable chutes (see fig. 1), which facilitate the distribution of the fruit to all parts of the end bin. The size of the fruit which passes into the end bin is, of course, regulated by the wheeland-lever adjusters at the end of the machine. 
The sloping bins are without partitions, so that the packers are free to station themselves at any place where fruit of the desired size is to be found. The range of size at any point furnishes the packer with the slight variation that customarily appears between the fruit in the top and in the bottom of the baskets in packing the 6-basket carrier.
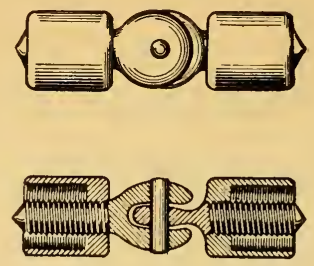

FIG. 6 .

If the grower wishes to pack bushels or hampers, and does not wish to arrange each individual specimen in the container, he can alter the bins slightly and run the peaches into the shipping package in the usual jumble pack.

Note. - A set of nine working drawings for this machine may be secured from the Bureau of Markets for $\$ 2$. Letters of patent No. 1,338,286 have been issued on this machine to Mr. J. F. Barghausen, of the Department of Agriculture. Free use of the invention is dedicated to the people of the United States.

ADDITIONAL COPIES

OF THIS PUBLICATION MAY BE PROCURED FROM THE SUPERINTENDENT OF DOCUMENTS

GOVERNMENT PRINTING OFFICE WASHINGTON, D. C.

AT

5 CENTS PER COPY 

LIBRARY OF CONGRESS

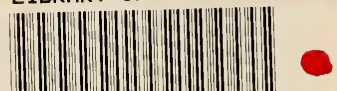

00009179331 
Metal Edge, Inc. 2007 PA.T. 
LIBRARY OF CONGRESS

|||||||||||||||||||||||||||||||||||||||

๑ 0009179331 